Max-Planck-Institut für demografische Forschung

Max Planck Institute for Demographic Research

Konrad-Zuse-Strasse 1 - D-18057 Rostock · GERMANY

Tel +49 (0) 3812081 - 0; Fax +49 (0) 3812081 - 202;

http://www.demogr.mpg.de

MPIDR WORKING PAPER WP 2007-012

MARCH 2007

Towards smaller family size in Egypt,

Morocco and Turkey:

overall change over time or

socio-economic compositional effect?

Agata V. D’Addato (daddato@demogr.mpg.de)

Daniele Vignoli (vignoli@demogr.mpg.de)

Sutay Yavuz (yavuz@demogr.mpg.de)

This working paper has been approved for release by: Gerda Ruth Neyer (neyer@ demogr.mpg.de)

Deputy Head of the Laboratory of Contemporary European Fertility and Family Dynamics.

(C) Copyright is held by the authors.

Working papers of the Max Planck Institute for Demographic Research receive only limited review. Views or opinions expressed in working papers are attributable to the authors and do not necessarily reflect those of the Institute. 


\title{
Towards smaller family size in Egypt, Morocco and Turkey: overall change over time or socio-economic compositional effect?
}

\author{
Agata V. D’Addato ${ }^{(1)}$ - Daniele Vignoli ${ }^{(1)} \&(2)$ - Sutay Yavuz ${ }^{(1)}$ * \\ (1) Max Planck Institute for Demographic Research, Rostock (Germany). \\ (2) Department of Demography, University of Rome "La Sapienza" (Italy).
}

\begin{abstract}
:
The whole region of the South and East Mediterranean exhibits a profound fertility transition with marked differences in the pace of fertility declines among the countries. The authors choose three representative countries: Egypt, Morocco and Turkey. Determinants of the propensity towards smaller family size are investigated as scrutinizing the development in the pattern of third births, which represents the critical step in the transitional process for these countries. The authors are particularly interested in verifying whether the decline of higher-order births is significantly driven by an overall societal change over time or by compositional change over different socio-economic segments of the female population. Evidence is found that overall societal changes have mainly driven the decline in large family size, though, to a much lesser extent, compositional changes are important too.
\end{abstract}

\section{Introduction}

The widespread image of fertility in the Mediterranean region is that it is highly polarized between the Northern and Southern shores. While lowest-low fertility levels have been characterizing the countries of the Northern shore since the 1990s, a high fertility was characterizing the South and East Mediterranean countries. However, a closer look at the present picture reveals a significantly different image. The fertility levels of Northern and Southern countries have been converging due to the ongoing rapid fertility transition in the latter region since the 1960s (Mencarini and Salvini, 2003). Nevertheless, within this generally converging pattern, differences and divergences still persist among the South and East Mediterranean countries, as highlighted in previous comparative studies (Courbage, 1999 ${ }^{\mathrm{a}}$; Di Comite and Moretti, 1999).

Bearing in mind these previous observations, the aim of this study is to investigate the differences characterizing the South and East shores of the Mediterranean basin. For this reason, three countries of this area were selected to represent different fertility transition patterns: Egypt, Morocco and Turkey. The patterns differ in more than one respect: the onset of fertility transition in these countries started at different times; it followed different paths at different paces; and it currently displays different magnitudes of fertility decline. The fertility decline in Egypt, which started at the beginning of the 1960s, became weaker during the 1990s; the Total Fertility Rate (TFR) is now stable at above 3 children per woman. In Morocco, although the fertility transition began relatively late - in the mid-1970s - it developed rapidly and the TFR is now at the level of 2.5 children per woman. Finally, Turkey saw the earliest drop in

\footnotetext{
* The names of the authors are listed in alphabetical order.
} 
fertility - beginning during the 1950s - and by the end of the twentieth century the fertility was already approaching the replacement level.

Although they currently have different magnitudes of fertility decline, the three countries under investigation are all moving towards a modern parity-specific fertility limit (Mencarini and Salvini, 2003). In this sense, as the "two-child norm" spreads among different segments of the society, the third child represents the pivotal point in the fertility transition, so the propensity to experience a third birth might be considered as a "critical" indicator that marks the advanced stage of fertility transition. For these reasons, the present study focuses on the mechanisms behind the propensity to establish smaller family size in Egypt, Morocco and Turkey, examining the progression to third-order fertility. Has this behaviour in these countries essentially been driven by some particular population subgroups with higher socioeconomic standards? In other words, does it appear as a result of compositional changes? Or alternatively, has it been an attribute of all the socio-economic segments of the population - can it be said to be due to an overall social change over time in these countries?

The paper is organized as follows. In Section 2, the different fertility developments in Egypt, Morocco and Turkey are described and an overview of selected social and economic determinants of fertility is provided. In Section 3, the role of the diffusion process in fertility transition is highlighted and the research hypotheses are stated. Section 4 deals with the explanation of the data and methods used in the empirical part of the study. In Section 5, the childbearing patterns of the three countries are analyzed in order to show that the transition from second to third birth constitutes the crucial step in their fertility decline. The determinants of the progression to the third child are then scrutinized through hazard models in Section 6. Finally, Section 7 is devoted to a discussion and concluding remarks.

\section{Explaining fertility developments in Egypt, Morocco and Turkey: the role of social and economic factors}

Different patterns, magnitude and pace have been characterizing the fertility developments of Egypt, Morocco and Turkey during the last five or six decades. To consider the developments since then, it is helpful to know that there was a relatively common starting position: according to the United Nations (2006), the TFR was around 7 children per woman at the beginning of the 1950s in all three of the countries chosen (Figure 1).

In Turkey, the trend in fertility decline was rapid and almost stable from the 1950s to 1980s (Duben and Behar, 1991). During the 1950s and 1960s, social and economic modernization spread to rural and undeveloped areas and fertility started to decline in the whole country, mainly due to changes in marriage patterns (Akin and Bertran, 1996). The pace of decline reached its zenith in the 1970s, and then it slowed down after the 1980s, with the TFR approaching the level of two children per woman (Hancioğlu et al., 2004; Yavuz, 2006).

In Egypt, fertility started to decline in the 1960s. After an initial fast decline between 1960 and 1970, the pace of the decline almost stalled, with fertility remaining around 5.5 children per woman until the beginning of 1980s. After this, the decline trend regained momentum: the TFR fell from 6 to 4 children per woman in a decade. However, it stagnated again in the 1990s; the discontinuous nature of the 
trend has recently been the subject of much discussion in the literature (Eltigani, 2003; Engelhardt, 2004; Giusti and Vignoli 2006; Vignoli, 2006).

Among the three countries chosen, the one where the fertility transition began the latest is Morocco. In fact, at the beginning of the 1970s the fertility level was still as high as 7 children per woman. Having started late, the decline in fertility in Morocco has nonetheless been continuous and swift since then (Deane Abernety, 2002; D'Addato, 2006 ${ }^{\mathrm{a}}$ ). In particular, the 1980s saw a substantial change in reproductive behaviour.

In order to understand in depth the determinants of differential fertility outcomes, it is helpful to focus on the specific mechanisms influencing the transitional process.

Figure 1 - Fertility trends in Egypt, Morocco and Turkey, 1950-2000.

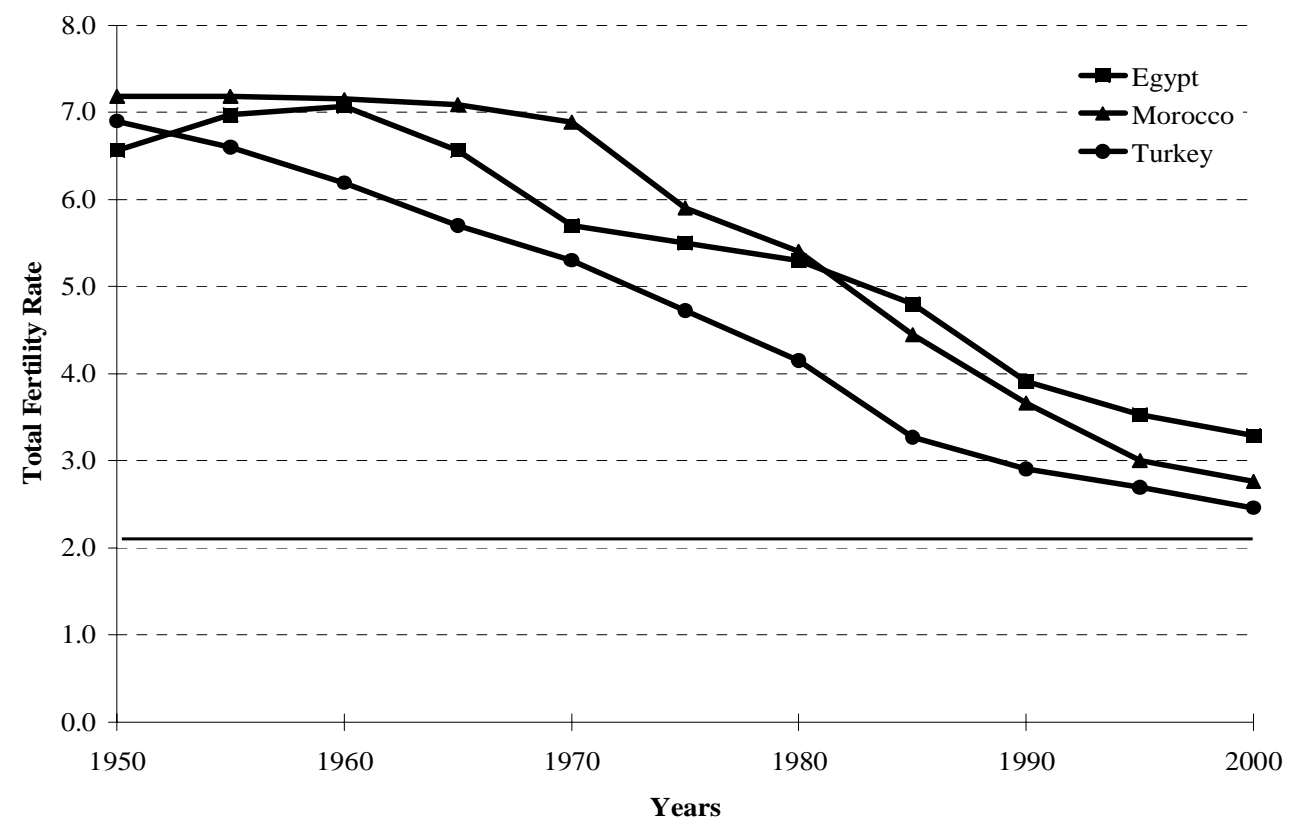

Source: United Nations, 2006.

The connection between socio-economic development and fertility decline has been examined extensively in the demographic literature. According to the classical version of demographic transition theory, the transition from high to low fertility levels is intimately related to industrialization and modernization (Notestein, 1953). The demographic transition theory asserts that as a result of socio-economic development, the benefits gained from children decline over time while the costs of having children increase (Easterlin, 1975; Becker, 1991).

Easterlin proposed a general framework in which economic models of demand for fertility were combined with demographic analysis of the supply of children (Easterlin 1975; Easterlin and Crimmins, 1987). According to this framework, the observed fertility results from the interaction of three factors: the demand for children; the supply of children; and the psychological, economic, health and social costs of fertility control. The demand for children is directly related to household income and inversely related to the strength of the desire for goods relative to that for children. The supply of children depends on natural fertility and infant/child mortality. Furthermore, the relationship between these two factors - demand for and supply of 
children - is in itself a determining factor for the motivation behind modern family limitation. If the supply side falls short of demand side no desire arises to limit fertility; in the opposite case, if supply side exceeds the demand side, there is an excess of children compared to the couples' desired family size, and fertility will be reduced. Lower demand for children is a necessary but not sufficient condition for fertility limitation. As Easterlin $(1975,1987)$ maintains, the question of whether fertility control will actually be used depends upon the importance of the costs of fertility regulation compared with the desire to limit fertility. In other words, the demand-supply-regulation cost relationship is seen as a determinant of the fertility behaviour in this framework.

Following the above-mentioned approach, the authors of the current study examine modernization and fertility decline linkage in the three countries under investigation in the last two decades of the twentieth century. In fact 1980-2000 is the critical era in terms of convergence towards modern family regulation in Egypt, Morocco and Turkey. The authors have therefore illustrated changes in selected macro social and economic indicators that might have influenced the pace of fertility decline (Table 1).

In the process of modernization, major factors resulting in a decrease in the demand for children can be seen to be: increasing per capita income, urbanization, women's education, and women's labour force participation. The subjective preferences about child quality rise with increasing income at the expense of the number of children. The data presented in Table 1 show that the gross domestic product per capita (GDP) has substantially increased, especially in Egypt and Turkey, during the time considered by this study. In Morocco, the increase in GDP was relatively slow in 1990-2000 compared to 1980-1990.

As empirical studies have shown, in developing countries the socio-economic structural factors have a stronger impact in urban areas than in rural areas (e.g. Bulatao and Lee, 1983). Urbanization usually covers the rising income level, opportunity of education and employment, cultural diversity, openness to change, and family planning program efforts. Thus urban settings facilitate the transition to modern family limitation (Rodriguez and Cleland, 1981). The overall societal change towards urbanization - the increase in the proportion of urban population - gives a good indication of decreasing demand for children. Approximately 44 percent of the whole population in Egypt and Turkey were living in urban areas in 1980, while this proportion was around 41 percent in Morocco. Between 1980 and 1990, the urban percentage of the population increased around 35 in Turkey and 17 in Morocco, whereas in Egypt the distribution of population between urban and rural showed no change. Thereafter, during 1990-2000, the proportion of urban population increased by 9 percent in Turkey and 15 percent in Morocco, while in Egypt it decreased by 3 percent. 
Table 1 - Comparison of selected social and economic factors in 1980, 1990 and 2000, Egypt, Morocco and Turkey.

\begin{tabular}{|c|c|c|c|c|c|c|c|c|c|}
\hline \multirow{2}{*}{ Factors } & \multicolumn{3}{|c|}{1980} & \multicolumn{3}{|c|}{1990} & \multicolumn{3}{|c|}{2000} \\
\hline & Egypt & Morocco & Turkey & Egypt & Morocco & Turkey & Egypt & Morocco & Turkey \\
\hline Real GDP per capita (\$PPP) & 2,109 & 2,589 & 3,657 & 2,689 & 3,096 & 4,830 & 3,253 & 3,195 & 5,731 \\
\hline Life expectancy at birth (years) & 56.5 & 55.7 & 59.5 & 63.9 & 65.5 & 66.1 & 67.6 & 67.8 & 68.6 \\
\hline Infant mortality rate (per 1000 live births) & 107.0 & 90.0 & 93.0 & 65.0 & 57.0 & 54.0 & 46.0 & 46.0 & 45.0 \\
\hline Urban population $(\%)$ & 43.8 & 41.3 & 43.8 & 43.4 & 48.4 & 59.2 & 42.1 & 55.5 & 64.7 \\
\hline Female adult literacy $(\%)$ & 24.7 & 15.5 & 53.8 & 33.6 & 24.9 & 66.4 & 43.8 & 36.1 & 76.5 \\
\hline Women in the labour force $(\%)$ & 26.5 & 33.5 & 35.5 & 27.0 & 34.6 & 34.6 & 30.4 & 34.7 & 37.6 \\
\hline \multicolumn{10}{|l|}{ Contraceptive usage: } \\
\hline All methods (\%) & 24.1 & 19.0 & 53.0 & 47.6 & 41.5 & 62.6 & 56.1 & 63.0 & 71.0 \\
\hline Modern methods (\%) & 23.0 & 16.1 & 23.9 & 44.3 & 35.5 & 34.5 & 53.9 & 54.8 & 42.5 \\
\hline Traditional methods (\%) & 1.1 & 2.9 & 29.1 & 3.3 & 6.0 & 28.1 & 2.2 & 8.2 & 28.5 \\
\hline
\end{tabular}

Source: United Nations, 2005. For the contraceptive usage: U.S. Census Bureau, 2006.

Note: GDP per capita at purchasing power parity $(P P P)$ is estimated based on the purchasing power of currencies rather than current exchange rates. For further information see UNDP, 2006.

Life expectancy and infant mortality refers to periods 1980-1985, 1990-1995 and 1995-2000.

Urban population refers to the mid-year population in urban areas, estimated by Population Division of the United Nations Secretariat. "Urban" is defined according to the national census definition incorporated in the latest available census. For further information see UNDP, 2006.

Contraceptive usage refers to the percent distribution of currently married women (15-49) by contraceptive method currently used. Modern methods refer to pill,

IUD, injection, diaphragm/foam/jelly, condom, female/male sterilization and implant. Traditional methods refer to periodic abstinence, withdrawal, prolonged breastfeeding and other methods. 
Rising women's educational levels may largely lead to a decline in demand for children: not only since it may increase the opportunity cost of children, resulting in a delayed entry into motherhood, but also because it empowers women, raising their status in family and society (Jejeebhoy, 1998). More than half of the women were literate $^{1}$ in Turkey in 1980, while in Egypt and Morocco these proportions were considerably lower. However, the level of female literacy was higher in Egypt (25 percent) than in Morocco (15 percent). From 1980 to 1990, this indicator increased 60 percent in Morocco, 26 percent in Egypt, and 24 percent in Turkey. In Morocco and Egypt the share proceeded to rise rapidly from 1990 to 2000 as well. As these figures show, the increase in female adult illiteracy and the decrease in fertility level are highly concomitant in Morocco and Turkey. In Egypt the female adult illiteracy has also risen but corresponding fertility decline is less significant in this country. On the contrary, comparing the proportions of women in the labour force in 1980 and 2000, it appears that in Egypt there has been a considerable rise of 15 percent, while in the other two countries these proportions have not changed since 1980. This may show that the explanation referring to the opportunity costs of childbearing may not be very relevant for these countries, since female labour force participation has not changed while fertility has significantly declined. In reality, the definition and measure of female labour force participation is itself a complex issue because in the developing countries the boundaries are not so visible between formal and informal, or paid and unpaid, work activities (Paterno et al., 2006).

As for the supply side, high mortality would lead to a decrease in the supply of children due to so called "replacement" effect mechanism: parents replace children who have died in order to achieve their desired surviving number of children (Scrimshaw, 1978). Improvements in public health and medical care, in the prospects of general socio-economic development, and the continuing modernization process have tended to lead to an increase in two factors that in turn increase the potential supply of children: natural fertility and survival probability of children. The improvement of health conditions thereby makes it easier for parents to achieve their number of desired surviving children with a lower number of births. In the case of this study, the estimated life expectancy at birth increased by 12 years in Morocco, 11 years in Egypt, and 9 years in Turkey from 1980 to 2000. Likewise, important improvements in infant mortality rates occurred in all the countries over time. Improvements in both indicators in each of the countries show that the fertility decline parallels the developments in socio-economic and health conditions (Figure 1).

As for the third determinant of fertility mentioned in Easterlin's framework, the decreasing costs of fertility regulation may facilitate the implementation of a couple's desire for a smaller family. In all three countries, the 1960s marked the adoption of anti-natalist population policies. The first family planning was launched in Egypt in 1965; the prohibition of the advertisement, sale and distribution of contraception ended in Turkey in 1965; and in Morocco this occurred in 1967 (Courbage, 1994; Hancioğlu, 1997; Eltigani, 2001). The increasing diffusion of contraceptive practices was notable in Egypt and Morocco during the 1980s and 1990s, although the levels of contraceptive usage in the former country were at much lower levels than in the latter one. However, while the consistent increase in contraceptive use continued throughout the 1990s in Morocco, contraceptive practice seems to have been at a plateau since the early 1990s in Egypt. In Turkey, on the other hand, both prevalence and practice of contraception seem to be different. High standards of contraceptive

\footnotetext{
${ }^{1}$ Note that female adult literacy is taken as a proxy for female education in this section.
} 
practices had already been attained in the 1980s, when the proportion of married women using a family planning method represented half of the population (53 percent). The change in policy may have influenced contraceptive practices in this country, although the extent of this influence has remained a controversial issue. The policy change seems to change the contraceptive mix due to modern methods being made publicly available. However, couples relied more on methods implemented by males - withdrawal - throughout the 1980s and 1990s (SIS, 1996).

On the whole, the general course of the macro social and economic changes since 1980 illustrates a general development and continuing modernization process in each of the countries. However, the settings under investigation present a different evolution of the selected indicators. In Morocco, the relative change in the levels of urbanization, female literacy and especially in contraceptive prevalence in the last decade of the twentieth century was the strongest of the three countries analysed. This is in line with the existing literature, which attributes the fact that Morocco's fertility decline outpaces Egypt's ${ }^{2}$ to a stronger increase in these indicators (e.g. Courbage, 1994; Eltigani, 2000). In Turkey, higher socio-economic standards and contraceptive prevalence had already been attained in the 1990s; the fertility transition spread much earlier than in Egypt and Morocco.

\section{Is there a space for diffusion?}

As discussed in the previous section, the roles of changes in material conditions and in the social division of labour and resources that are associated with modernization are considered as potent forces driving the fertility decline. Nevertheless, the elaborations concerning the effect of socio-economic change on reproductive behaviour have been subject to several criticisms, too. Since the 1970s, the absence of a clear link between development indicators and onset and pace of fertility decline has been questioned by many studies, based on historical experience of developed countries and ongoing transitions in contemporary developing countries (Watkins, 1986; Cleland and Wilson, 1987; Watkins, 1987). The primary role of socio-economic factors in bringing about fertility transition is, thus, controversial; the influence of other additional factors can also make a substantial contribution. For instance, the role of culture (Lesthaeghe and Surkyn, 1988; Kertzer, 1997), the role of institutions (McNicoll, 1994), the direction of wealth flows (Caldwell, 1982), the networks and the social interaction (Bongaarts and Watkins, 1996), and the diffusion process (Casterline, 2001), are all concomitant factors acting together with socioeconomic development.

Among these further explanations, the role played by diffusion and social interaction processes in fertility declines is widely accepted (Bongaarts, 2006). Extensive literature exists on the diffusion theory, referring to an overarching model of social change in which attitudes and behaviour become more prevalent in a population through their spread from some individuals to others, through informal face-to-face social interaction, or at a distance through the mass media (Knodel and van de Walle, 1979; Caldwell, 2001; Casterline, 2001).

\footnotetext{
${ }^{2}$ Additionally, international migration may have played a different role in the two countries (Courbage, 1995 and $1999^{\mathrm{b}}$ ). The destination for Moroccan immigrants has been the Southern Mediterranean countries (mainly Italy and Spain), while the Egyptian immigrant workers mostly moved to the Arabic Peninsula's oil-rich countries. The effect of international migration on the society of origin has been proved to be important in the spread of fertility regulation in Morocco (D'Addato, 2006 ${ }^{\mathrm{b}}$ ).
} 
Social interaction can inhibit fertility change before a transition onset since it can be the source of resistance to the adoption of the birth control behaviour. But once innovative behaviour has been adopted by the trendsetters (generally people having higher socio-economic standards), the same factor can instead become a powerful force that accelerates the pace of transition in the rest of the population. Increasing social and economic development, in fact, proliferate the diffusion channels: the effect of mass media and other communication channels; or the multiplication of informal networks. Diffusion does not only refer to the spread of new technology and information, such as family planning practices, but also to the introduction of new preferences about childbearing. People may begin to imitate those people who already began to limit family size without experiencing a real change in their socio-economic circumstances. Once this process has largely run its course, the decline of large families in the advanced transitional stage becomes less closely tied to socioeconomic development. In this sense, late in the transition, the propensity towards smaller families for the lowest socio-economic groups becomes faster than it was.

The two sets of explanations - the role of socio-economic development and the diffusion process in accounting for fertility declines - should, in fact, be considered complementary and not competing (Montgomery and Casterline, 1996). For this reason, the research hypotheses in this study take both aspects into account.

In line with previous theoretical considerations, sharing the view that individual and socio-economic characteristics differentiate women's reproductive behaviour, the authors expect a higher probability of limiting family size among the more advanced socio-economic segments of the female population. They also wish to see to what extent these determinants differ in each country-specific setting. However, the propensity towards modern family limitation in the countries under study may not be solely attributable to the trendsetters, characterized by an urban background and higher educational attainment. In fact, increasing fertility control is expected to be a behaviour in diffusion, which has been adhered to by all segments of the population during the last two decades of the twentieth century.

\section{Data and model specification}

The study is based on recent retrospective survey data available in Egypt, Morocco and Turkey: Egypt Demographic and Health Survey (EDHS) 2000, Morocco Demographic and Health Survey (MDHS) 2003/04, and Turkey Demographic and Health Survey (TDHS) 2003. The 2000 EDHS, 2003/04 MDHS and 2003 TDHS, consist respectively of nationally representative samples of 15,573, 9,765 and 8,075 ever-married women aged 15-49. The comparable information across countries is collected through Demographic and Health Surveys by means of similar questionnaires and survey procedures followed in each country. These surveys provide information on background characteristics of women interviewed and include a wide range of questions on their reproductive histories. However, most of the other socio-economic characteristics (i.e. migration and employment histories) and also information on the proximate determinants of fertility (i.e. breastfeeding and contraceptive usage) have only been collected for the time of interview. This information cannot be used in conjunction with birth order because of the risk of performing an anticipatory analysis (Hoem and Kreyenfeld, 2006a and 2006b).

The empirical part of the work is carried out using event history techniques. The samples are analyzed separately for the three countries. For each country, the 
observation starts from 1981; cases are then right-censored at 2000 to allow a correct comparison in the same time span (1981-2000).

Firstly, the analysis examines the timing of childbearing patterns in the three countries. Two fertility summary measures from the Kaplan-Meier survival curves ${ }^{3}$ are estimated: a) the cumulative proportions of women of a given parity having a subsequent birth within 60 months of the previous birth, which is a measure of the quantum of fertility; b) the median ${ }^{4}$ length of the interval - in months - after which 50 percent of mothers had a subsequent child, which is a measure of the tempo of fertility.

Then the analysis focuses on the determinants of the progression to the third birth, since, as already mentioned, the declining tendency to have a third child is the crucial indicator that marks the transition to more modern fertility behaviour. Multiplicative intensity-regression models are thus estimated to measure the third-birth intensities for Egypt, Morocco and Turkey ${ }^{5}$. Woman's third-birth risk is defined as the probability of experiencing third birth within the next month; given her individual characteristics and that she has delivered a second birth by the beginning of the life segment. The baseline hazard (basic time factor) is the duration in months elapsed from the second birth (starting eight months after it). The baseline hazard is a piecewise constant function (i.e. the basic time factor is defined as a categorical variable), where the risks are assumed to be constant within each time interval but may vary across such intervals.

Because getting married remains the predominant social norm throughout these countries, and given that practically all births occur within marital unions, this study focuses on women currently married at the survey date. The analysis is therefore carried out on 9,662 Egyptian women, 6,172 Moroccan women and 5,429 Turkish women currently married ${ }^{6}$, aged $15-49$, who gave birth to a second child.

The selection of the socio-economic variables was obviously conditioned by the availability of comparable data for the three countries under investigation. In this respect, education of women ${ }^{7}$ and childhood place of residence are two basic variables reflecting the individuals' socio-economic profile.

The partner's characteristics are also believed to influence the likelihood to give birth to a third child. Therefore, the authors used a variable reflecting partner's educational attainment in the analysis.

\footnotetext{
${ }^{3}$ The Kaplan-Meier technique provides a solution to the censoring problem of cross-sectional data and the estimated survival curves present the probability of progression from parity $i$ to parity $i+1$ (Kleinbaum, 1996).

${ }^{4}$ Median duration estimation includes both closed and open birth intervals by the time of survey.

5 Beside the mechanisms governing women's choices at the individual level, the socio-cultural contextual factors may also represent a key interpretative issue. In fact, the macro impact of community factors and the different opportunities that the area of residence offers could also lead to a better understanding of the choices' determinants. However, a multilevel approach allowing the simultaneous inclusion in a single statistical model of both the micro (individual level) and macro (contextual level) components cannot be performed in this study, due to the lack of information on internal migration histories.

${ }^{6}$ In the three countries considered, divorce is still an issue far from being of major importance, so that it may not cause a large problem in the empirical analysis.

7 The inclusion of the highest level of education ever reached is justified by the assumption that individuals have already concluded their educational path at the time of second birth.
} 
Moreover, four time periods of equal length are included in the model (1981-1985, 1986-1990, 1991-1995 and 1996-2000), aiming at capturing the change over time of third-birth likelihood ${ }^{8}$.

The survival status of first child in the analysis is also introduced in order to catch the "replacement" effect due to the loss of a child". The remaining two covariates, namely the age at first union and the length of previous birth interval, can be seen as demographic control variables.

The overall compositions of the study populations are presented in Table 2, which contains occurrences (third births) and exposure times (of two-child mothers) by each of the variables used in the modelling procedure. Particularly noticeable are: the low number of women having experienced the loss of the first child in the Turkish sample; the lower proportion of Moroccan respondents having spent their childhood in urban areas; the higher proportion of highly educated women in Egypt. The composition of educational groups is actually very divergent in the three settings. On the whole, the general structure implies high polarization among women in Egypt. In Morocco it is interesting to point out the small proportion of two-child highly educated mothers, which is consistent with the fairly low proportion of highly educated women in the whole population (Azelmat et al., 2005). Finally, in Turkey, women are generally to be found in the middle level of schooling.

\footnotetext{
${ }^{8}$ The choice of these categorizations is due to the fact that common periods could not be identified representing relevant socio-economic and political events in each of the countries under investigation.

${ }^{9}$ The authors take into account the survival status of the first child at the beginning of their episode as a covariate but they do not consider the survival status of the second child. In the latter case, in fact, they would chase for two different events within the same episode: mortality of the second child and birth of the third child. In such circumstance, it might be unclear whether the baseline stands for mortality or fertility event (and also these two events might be endogenous).
} 
Table 2 - Transition to third birth: exposure (in person-months) and events in the study populations.

\begin{tabular}{|c|c|c|c|c|c|c|c|c|c|c|c|c|}
\hline \multirow{3}{*}{ Covariates } & \multicolumn{4}{|c|}{ Egypt } & \multicolumn{4}{|c|}{ Morocco } & \multicolumn{4}{|c|}{ Turkey } \\
\hline & \multicolumn{2}{|c|}{ Exposures } & \multicolumn{2}{|c|}{ Events } & \multicolumn{2}{|c|}{ Exposures } & \multicolumn{2}{|c|}{ Events } & \multicolumn{2}{|c|}{ Exposures } & \multicolumn{2}{|c|}{ Events } \\
\hline & Abs. val. & $\%$ & Abs. val. & $\%$ & Abs. val. & $\%$ & Abs. val. & $\%$ & Abs. val. & $\%$ & Abs. val. & $\%$ \\
\hline \multicolumn{13}{|l|}{ Period } \\
\hline 1981-1985 & 82,456 & 22.3 & 2,435 & 31.6 & 44,498 & 20.5 & 1,270 & 26.1 & 18,096 & 8.0 & 293 & 14.3 \\
\hline $1986-1990$ & 67,185 & 18.2 & 1,687 & 21.9 & 36,315 & 16.7 & 914 & 18.7 & 43,646 & 19.3 & 509 & 24.8 \\
\hline $1991-1995$ & 91,445 & 24.8 & 1,673 & 21.7 & 47,499 & 21.8 & 916 & 36.4 & 68,994 & 30.5 & 584 & 28.5 \\
\hline $1996-2000$ & 128,068 & 34.7 & 1,901 & 24.7 & 89,271 & 41.0 & 1,775 & 36.4 & 95,875 & 42.31 & 663 & 32.31 \\
\hline \multicolumn{13}{|l|}{ Age at marriage } \\
\hline$\leq 19$ & 179,505 & 48.6 & 4,726 & 61.4 & 117,592 & 54.0 & 2,928 & 60.1 & 134,147 & 59.2 & 1,452 & 70.9 \\
\hline $20-22$ & 93,312 & 25.3 & 1,727 & 22.4 & 49,191 & 22.6 & 1,103 & 22.6 & 60,480 & 26.7 & 415 & 20.3 \\
\hline $23-25$ & 54,027 & 14.6 & 805 & 10.5 & 28,065 & 12.9 & 516 & 10.6 & 23,579 & 10.4 & 138 & 6.7 \\
\hline $26+$ & 42,310 & 11.5 & 438 & 5.7 & 22,735 & 10.4 & 328 & 6.7 & 8,405 & 3.7 & 44 & 2.2 \\
\hline \multicolumn{13}{|l|}{ Previous birth interval } \\
\hline Less than 2 years & 167,688 & 45.4 & 4,033 & 52.4 & 75,029 & 34.5 & 2,270 & 46.6 & 83,989 & 37.1 & 1,120 & 54.7 \\
\hline 2 years and more & 201,466 & 54.6 & 3,663 & 47.6 & 142,554 & 65.5 & 2,605 & 53.4 & 142,622 & 62.9 & 929 & 45.3 \\
\hline \multicolumn{13}{|l|}{ Childhood place of residence } \\
\hline Rural & 189,454 & 51.3 & 4,789 & 62.2 & 137,045 & 63.0 & 3,586 & 73.6 & 99,308 & 43.8 & 632 & 30.8 \\
\hline Urban & 179,700 & 48.7 & 2,907 & 37.8 & 80,538 & 37.0 & 1,289 & 26.4 & 127,303 & 56.2 & 1,417 & 69.2 \\
\hline \multicolumn{13}{|l|}{ Woman's educational level } \\
\hline No education/primary incomplete & 193,508 & 52.4 & 5,182 & 67.3 & 180,233 & 82.8 & 4,389 & 90.0 & 39,574 & 17.5 & 764 & 37.3 \\
\hline Primary complete/secondary incomplete & 45,862 & 12.4 & 892 & 11.6 & 26,073 & 12.0 & 373 & 7.7 & 153,696 & 67.8 & 1,199 & 58.5 \\
\hline Secondary complete/higher & 129,784 & 35.2 & 1,622 & 21.1 & 11,277 & 5.2 & 113 & 2.3 & 33,341 & 14.7 & 86 & 4.2 \\
\hline \multicolumn{13}{|l|}{ Husband's educational level } \\
\hline No education/primary incomplete & 152,003 & 41.2 & 3,989 & 51.8 & 162,679 & 74.8 & 4,044 & 83.0 & 10,783 & 4.8 & 223 & 10.9 \\
\hline Primary complete/secondary incomplete & 62,126 & 16.8 & 1,379 & 17.9 & 30,128 & 13.8 & 504 & 10.3 & 146,751 & 64.8 & 1,472 & 71.8 \\
\hline Secondary complete/higher & 155,025 & 42.0 & 2,328 & 30.2 & 24,776 & 11.4 & 327 & 6.7 & 69,077 & 30.5 & 354 & 17.3 \\
\hline \multicolumn{13}{|l|}{ Survival status of first child } \\
\hline Alive at 2nd birth & 337,346 & 91.4 & 6,606 & 85.8 & 196,756 & 90.4 & 4,217 & 86.5 & 215,842 & 95.2 & 1,761 & 85.9 \\
\hline Died before 3rd conception & 31,808 & 8.6 & 1,090 & 14.2 & 20,827 & 9.6 & 658 & 13.5 & 10,769 & 4.8 & 288 & 14.1 \\
\hline Total & 369,154 & & 7,696 & & 217,583 & & 4,875 & & 226,611 & & 2,049 & \\
\hline
\end{tabular}

Source: Own elaborations on EDHS, 2000; MDHS, 2003/04; TDHS, 2003. 


\section{A first glance at childbearing patterns: limiting and spacing of births}

In this section the fertility differentials in the three countries under study are examined from a birth-order perspective. Firstly, quantum differences of fertility are investigated. Figure 2 presents the cumulative proportions of ever-married women at each parity who progressed to the next parity within five years after a preceding birth, from marriage up to parity six.

The proportions of the surveyed Egyptian, Moroccan and Turkish women who reached the first parity within the first five years of marriage are very high and they do not show large differences between the three countries (Figure 2): 94 percent in Egypt, 90 percent in Morocco, and 92 percent in Turkey. This is in line with the fact that childbearing represents the main purpose of marriage in Muslim societies (Fargues, 1988 and 2003). Nevertheless, after the first parity, different patterns can already be observed in the three countries in the proportion of ever-married women reaching the succeeding parities. Specifically, the proportion of Egyptian women who went on to have a second birth within five years is quite high: 91 percent. By contrast, among the Moroccan women, the proportion of women progressing to the second birth within five years was 82 percent, and in Turkey it is considerably lower, around 76 percent.

The decline of the proportion of Turkish mothers is clearly visible at the progression from second to third birth, while the majority of their Egyptian and Moroccan counterparts proceed to higher-order parity. Namely, in Turkey the proportion of two-child women reaching third parity within five years is 52 percent, whereas in Egypt and in Morocco the values are considerably higher: 78 percent and 74 percent, respectively. In the time-span between the marriage and the transition to parity four, the emerging Turkish fertility pattern seems to become similar to a typical low-fertility pattern of a developed setting (e.g. Andersson, 2000). From the transition to fifth - and more clearly to sixth - parity the proportion of women reaching higher order births nearly converges with the Egyptian and Moroccan counterparts. This peculiar parity progression pattern of Turkey suggests the presence of two different population sub-groups in the country - one more "modern" and one more "traditional" - with different reproductive behaviours ${ }^{10}$. As concerns Egypt and Morocco, the trends are slightly similar; however, at each subsequent parity Moroccan women are less likely to go on to have another child than their Egyptian counterparts.

The second summary measure is the median length of the interval which indicates the tempo of the fertility patterns (Figure 3). As expected, the median length of the interval between marriages and first birth is quite short and slightly similar in all three countries: around 13 months in Egypt, 15 months in Turkey, and 17 months in Morocco. This finding is confirmed by the direct estimates of the median age at first marriage and the median age at first birth of women aged 25-49 (Table 3).

Following the first birth, Figure 3 shows that the speed of childbearing is the fastest in Egypt (the median ranges between 13 and 39 months for all the intervals), whereas the median length of the birth interval ranges between 17 and 40 months in Morocco, and 15 and 57 months in Turkey. The results also indicate that, until parity two, the spacing of childbearing is very similar in Morocco and Turkey. By contrast, from the second to the sixth parity, the tempo becomes much slower in Turkey than in

\footnotetext{
${ }^{10}$ This may reflect the two distinguished fertility developments followed by women according to their mother-tongue; namely, between "Turkish" and "Kurdish" speaker women (Yavuz, 2006).
} 
Egypt and Morocco: this not only means that a smaller proportion of Turkish women carry on to higher order parity, they also do so more slowly.

To sum up, a smaller proportion of Turkish women progress to higher parity, and the duration of birth interval in this country is longer than in Egypt and Morocco. This brief look at the general childbearing patterns has also indicated that third birth represents the critical component of fertility change that differentiates the three considered countries.

Figure 2 - Cumulative proportion of women reaching the next parity within 60 months after a preceding birth, 1981-2000.

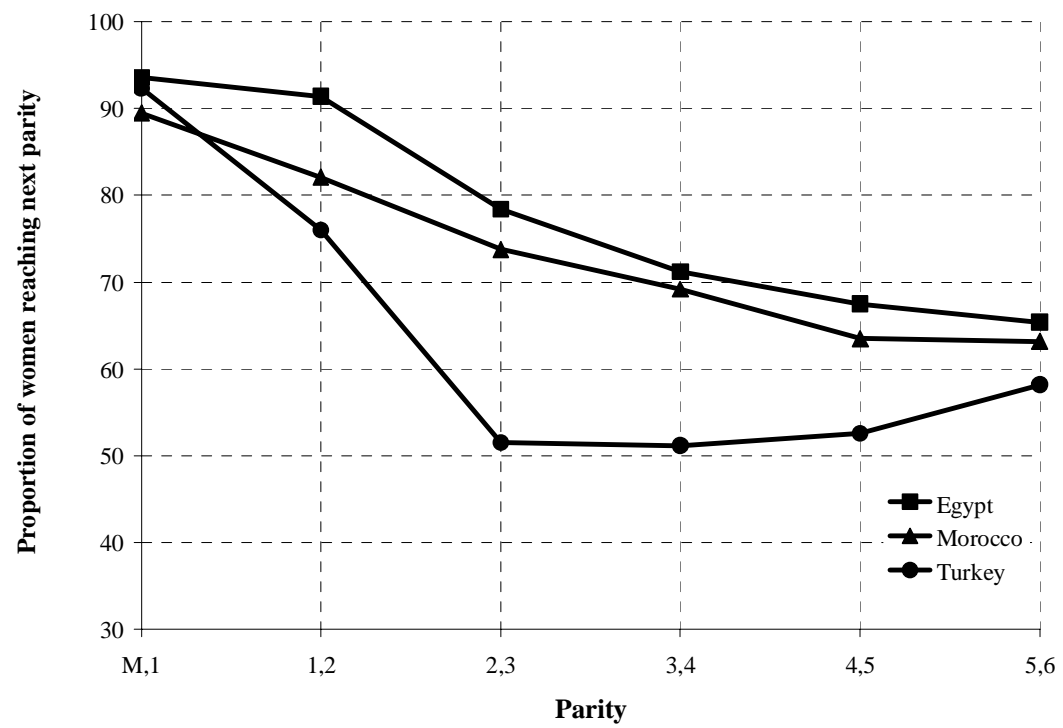

Source: Own elaborations on EDHS, 2000; MDHS, 2003/04; TDHS, 2003.

Note: Kaplan-Meier survival curves estimates.

Figure 3 - Median length of birth intervals (in months), where 50 percent of mothers had a subsequent child, according to parity order, 1981-2000.

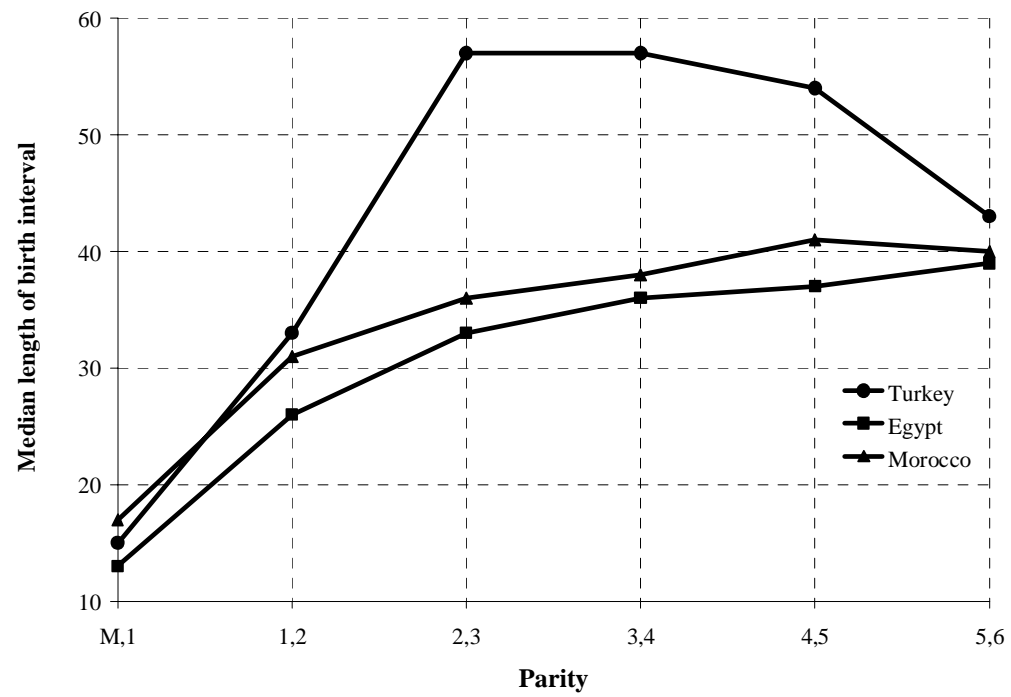

Source: Own elaborations on EDHS, 2000; MDHS, 2003/04; TDHS, 2003.

Note: Kaplan-Meier survival curves estimates. 
Table 3 - Median ages at marriage and at first birth in Egypt, Morocco and Turkey.

\begin{tabular}{|c|c|c|c|}
\hline & Egypt (2000) & Morocco $(2003 / 04)$ & Turkey (2003) \\
\hline Median age at marriage (25-49) & 19.5 & 21.4 & 20.0 \\
\hline Median age at first birth (25-49) & 21.6 & 23.9 & 21.8 \\
\hline
\end{tabular}

Source: El-Zanaty and Way, 2001; Hacettepe University, 2004; Azelmat et al., 2005.

Note: Median ages estimated from ever-married women.

\section{Third-birth developments in Egypt, Morocco and Turkey}

The analysis of the determinants of third-birth intensities was performed in two steps. The authors first estimated the purely demographic models that present relative risks of having the third birth for the period variable. This first step demonstrates period trends in the third-birth development after controlling for the effect of compositional changes among the women over age at first marriage and by the length of previous birth interval. In the second step, some selected socio-economic variables were added to the models that provide information on how women's socio-economic characteristics affect their propensity of giving birth to the third child. The addition of these variables might also result in modifications in the effect of the calendar period factor; the modified outcome (if any) should then be interpreted as an effect of the additional control of the compositional changes, from one period to another, over different socio-economic segments of the female population.

Figure 4 presents the third-child intensities by the gross effect of the calendar period for the three countries separately, showing the third-birth intensities in 19861990, 1991-1995 and 1996-2000 relative to the corresponding intensity in 1981-1985. These risks are obtained from the estimation of a separate model for each country without including any of the socio-economic variables. The results show that thirdbirth risks decreased with a very similar pattern for all the countries during the second half of the 1980s. However, in the 1990s, birth risks declined to different extents in Egypt, Morocco and Turkey. In the former two countries the relative decline is moderately stronger than in Turkey, where the relative decline levels off; note that fertility was already at lower levels at the end of the period.

In order to disentangle to which extent the fertility decline is driven by the populations' compositional changes, a number of socio-economic variables were added to the model. Figure 5 displays the third-child intensities over time, after controlling for these additional socio-economic factors. The introduction of the explanatory socio-economic covariates modifies the effect of the calendar period only a little (see Figure 4): it still remains, in fact, a significant determinant of women's reproductive choices even when controlling for compositional changes. However, the third-order fertility developments differ among the countries: the modification over time is actually the weakest in Egypt, while it shows a stronger differential effect in Turkey and, to a substantially larger extent, in Morocco. This result is consistent with observations at the macro level showing a faster increase in the main socio-economic variables and in the prevalence of contraception from 1990 to 2000 in Morocco compared to Egypt and Turkey (Table 1). 
Figure 4 - Relative risks of the progression to the third birth by calendar period, 1981-2000 (for each country given relative to that in 1981-1985), standardized for the duration in months since the second birth, demographic control variables (age of women at marriage, length of previous birth interval and survival status of first child).

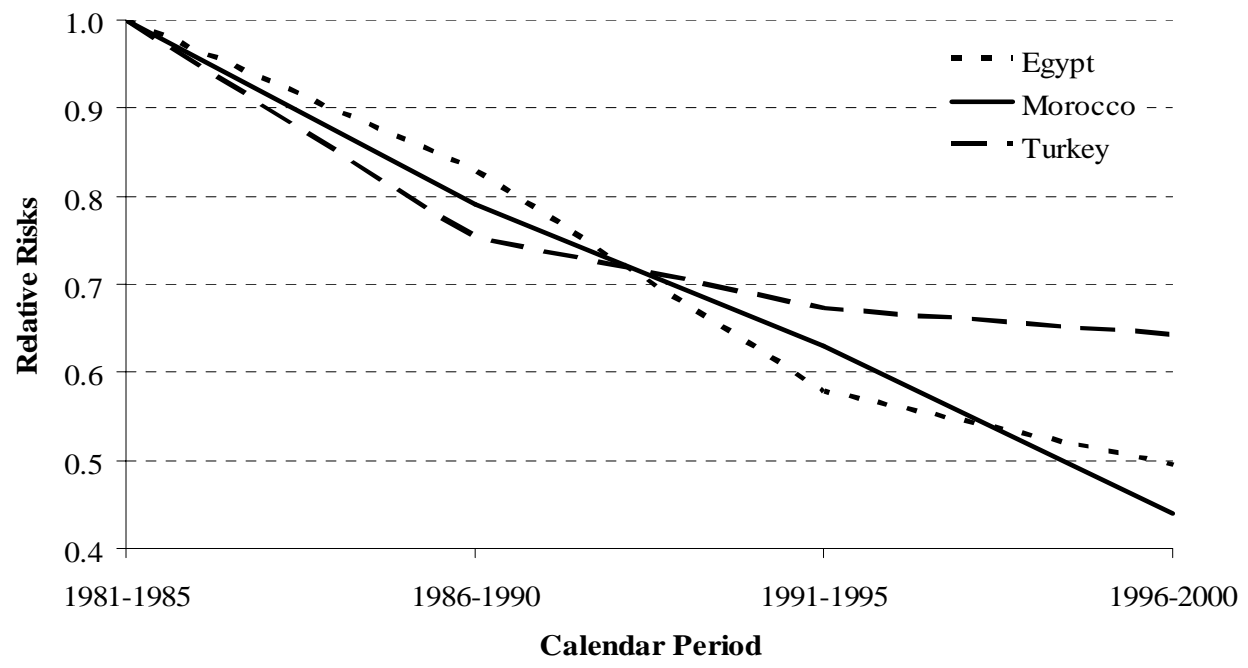

Source: Own elaborations on EDHS, 2000; MDHS, 2003/04; TDHS, 2003.

Figure 5 - Relative risks of the progression to the third birth by calendar period, 1981-2000 (for each country given relative to that in 1981-1985), standardized for the duration in months since the second birth, demographic control variables (age of women at marriage, length of previous birth interval and survival status of first child) and for the socio-economic variables (childhood place of residence, women and husbands' educational levels).

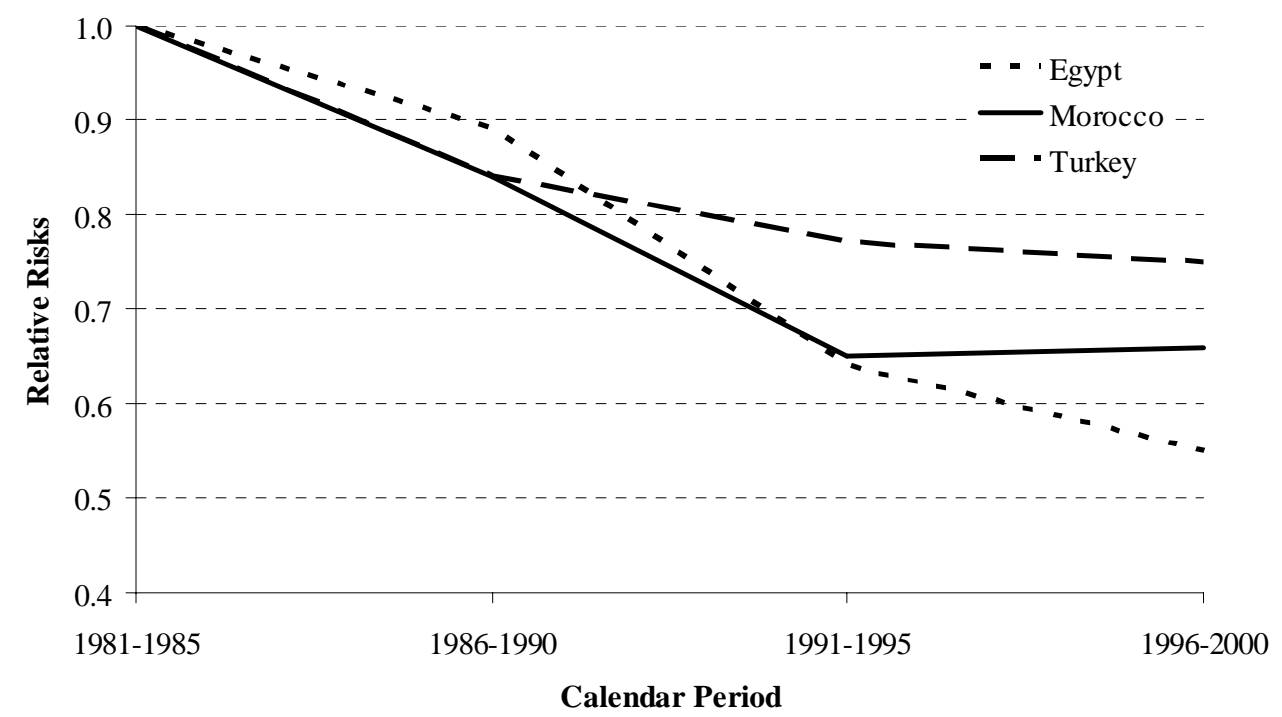

Source: Own elaborations on EDHS, 2000; MDHS, 2003/04; TDHS, 2003.

Table 4 presents the relative risks of third-child developments for two-child mothers according to childhood place of residence and spouses' educational level, standardized for the effect of calendar period, women's age at marriage, length of previous birth interval, and survival status of first child. Consistently with the existing 
literature in this topic, the childhood place of residence also turns out to be an important predictor of the fertility decrease: those who were brought up in a rural context experience a higher transition rate from second to third child. Women's education also appears to be a crucial factor in the course of third-order fertility reduction, net of the other observed variables. The impact of the educational attainment among women appears particularly strong in Turkey, where women with secondary and higher educational level reduce their third-child intensity by about 70 percent in comparison with those women without (or with primary incomplete) schooling. Finally, although weaker than that of wife's educational background, the impact of husband's education is found to have a significant influence on the propensity of giving birth to the third child in Turkey and Morocco. On the other hand, no significant effect of husband's educational level can be observed in Egypt.

Table 4 - Relative risks and significance level of third-child intensities for two-child mothers by selected socio-economic characteristics of the women, standardized for the duration in months since the second birth, demographic control variables (age of women at marriage, length of previous birth interval and survival status of first child) and calendar period.

\begin{tabular}{|c|c|c|c|c|c|c|}
\hline \multirow[b]{2}{*}{ Covariates } & \multicolumn{2}{|c|}{ Egypt } & \multicolumn{2}{|c|}{ Morocco } & \multicolumn{2}{|c|}{ Turkey } \\
\hline & $\begin{array}{c}\text { Relative } \\
\text { risks }\end{array}$ & $\begin{array}{c}\text { p- } \\
\text { values }\end{array}$ & $\begin{array}{c}\text { Relative } \\
\text { risks }\end{array}$ & $\begin{array}{c}\text { p- } \\
\text { values }\end{array}$ & $\begin{array}{c}\text { Relative } \\
\text { risks }\end{array}$ & $\begin{array}{c}\text { p- } \\
\text { values }\end{array}$ \\
\hline $\begin{array}{l}\text { Childhood place of residence } \\
\text { Rural }\end{array}$ & 1 & & 1 & & 1 & \\
\hline Urban & 0.80 & 0.000 & 0.72 & 0.000 & 0.81 & 0.000 \\
\hline Woman's educational level & & & & & & \\
\hline $\begin{array}{l}\text { No education/primary incomplete } \\
\text { Primary complete/secondary } \\
\text { incomplete }\end{array}$ & 0.82 & 0.000 & 0.87 & 0.024 & 0.55 & 0.000 \\
\hline Secondary complete/higher & 0.65 & 0.000 & 0.74 & 0.007 & 0.28 & 0.000 \\
\hline Husband's educational level & & & & & & \\
\hline $\begin{array}{l}\text { No education/primary incomplete } \\
\text { Primary complete/secondary } \\
\text { incomplete }\end{array}$ & 1.01 & 0.670 & 0.82 & 0.000 & 0.76 & 0.000 \\
\hline Secondary complete/higher & 1.03 & 0.449 & 0.78 & 0.000 & 0.62 & 0.000 \\
\hline
\end{tabular}

\section{Conclusions: overall change over time or socio-economic compositional change?}

Within the context of the well-known pattern of convergent fertility decline involving the South and East Mediterranean shores, this study aimed at highlighting differences and similarities between the declines in three selected countries. Each of them faces a different phase of the fertility transition: in Egypt the fertility is still above three children per woman; in Morocco the fertility is between three and two children per woman; and in Turkey the norm is currently around two children per woman.

The study's outcomes illustrate that different individual socio-economic profiles significantly determine women's reproductive behaviours. The results can thus be seen as supportive of the general idea that the segments of the population that have 
been more integrated into modernization trends are also characterized by a stronger preference towards smaller family size. By contrast, those women with a rural background, with a lower educational level, and married to less educated men, can be viewed as slow-movers in the fertility transition.

However, the analyses also show that the extent of the contribution of these factors is different in each country-specific context. In Turkey, which already showed significantly lower fertility rates in the 1980s, the findings reveal that there is a more selected group of women proceeding to higher-order births. The emerging fertility pattern seems quite similar to a typical low-fertility pattern of a developed setting in Turkey. It might be the case that due to the existence of a larger, more modern, secularized and urban sector, the individual socio-economic determinants in this country may have strengthened their influence on the pace of fertility decline. On the other hand, the development towards the decline of large families is less evident in Morocco and much less prevalent in Egypt.

In response to the authors' main research question, the results highlight a noticeable overall change over time of the third-birth intensity, even after controlling for compositional changes over different socio-economic population strata. The authors thus believe that the explanation of Bongaarts and Watkins (1996) about the globalization of fertility decline, intimately linked to the diffusion process of innovative behaviour, is particularly relevant in the interpretation of the convergence in family limitation towards a parity-specific level observed during the 1980s and 1990s in the countries under study. In fact, if at the onset of fertility transition the propensity to limit family size appears as a phenomenon driven by the trendsetters of the population, late in the transition this innovative behaviour spreads to all the other population segments. The persistent effect of an overall change over time is therefore consistent with the advanced stage of demographic transition in these countries.

It has also been demonstrated here that part of the decline in third-birth risks, although quite a small part, is due to compositional changes. The socio-economic compositional change is more pronounced in Morocco, where an increasing portion of the population is joining the socio-economic groups exhibiting lower fertility. This is related to the fact that from 1980 to 2000 the country in general experienced a more rapid change in urbanization, female literacy and especially contraceptive prevalence than the other two countries in the study.

On the whole, this analysis provides evidence for a progressive decline (at different paces) of third-birth likelihood in the last decade of the twentieth century in each of the countries. With the transition to third child being an indicator that marks the end of fertility transition, it can be expected that a more modern parity-specific fertility regulation, characterized by the "two-child norm", will prevail in the long run.

\section{Acknowledgments}

We acknowledge the support offered by Jan M. Hoem and the Max Planck Institute for Demographic Research. We are grateful to Gerda Neyer, Gunnar Andersson, and the members of the research team on "Fertility and Family Dynamics" of the Max Planck Institute for Demographic Research for comments and discussions on an earlier version of this paper. We also acknowledge Craig Meulen for the language editing. 


\section{References}

Akin, A. and Bertan, M. 1996. Contraception, Abortion and Maternal Health Services in Turkey. Ministry of Health, General Directorate of Mother and Child Health and Family Planning, Hacettepe University and Macro International Inc, Ankara and Calverton.

Andersson, G. 2000. "The impact of labour-force participation on childbearing behaviour: pro-cyclical fertility in Sweden during the 1980s and the 1990s". European Journal of Population, 16: 293-333.

Azelmat M., Ayad M., Abdelmoneim A. 2005. Enquête sur la Population et la Santé Familiale (EPSF) 2003/04, Ministère de la Santé Publique (Maroc), Macro International Inc, Ligue des États Arabes.

Becker, J.S. 1991. A Treatise on the Family, Harvard University Press, Cambridge.

Bongaarts, J. 2006. "The Causes of Stalling Fertility". Studies in Family Planning, 37(1): 1-16.

Bongaarts, J. and Watkins, S.C. 1996. "Social interactions and contemporary fertility transitions". Population and Development Review, 22(4): 639-682.

Bulatao, R. and Lee, R. 1983, Determinants of fertility in developing countries, Academic Press, New York.

Caldwell, J.C. 1982, The wealth flows theory of fertility decline. In Höhn C. and Mackensen R. (eds.), Determinants of fertility trends: theories re-examined, Ordina Editions, Liège.

Caldwell, J.C. 2001. The globalization of fertility behavior. In Bulatao R.A. and Casterline J.B. (eds.), Global Fertility Transition. Population and Development Review, supplement to volume 27, Population Council, New York.

Casterline, J.B. 2001, Diffusion processes and fertility transition: introduction. In Casterline J.B. (ed.), Diffusion processes and fertility transition. Selected Perspectives, National Academy Press, Washington.

Cleland, J. and Wilson C. 1987. "Demand theories of the fertility transition: An iconoclastic view". Population Studies, 41(1): 5-30.

Courbage, Y. 1994. "Demographic change in the Arab world: The impact of migration, education and taxes in Egypt and Morocco". Middle East Report, 24(5): 19-22.

Courbage, Y. 1995. Fertility Transition in the Mashriq and Maghrib: Education, Emigration and the Diffusion of Ideas. In Makhlouf Obermeyer C. (ed.), Family, Gender, and Population in the Middle East Policies in Context, The American University in Cairo Press.

Courbage, Y. 1999 ${ }^{\mathrm{a}}$. New Demographic Scenarios in the Mediterranean Region. Chaier 142, Ined/Puf.

Courbage, Y. 1999 ${ }^{\mathrm{b}}$. "Economic and political issues of fertility transition in the Arabworld-answers and open questions". Population and Environment: A Journal of Interdisciplinary Studies, 20(4): 353-380.

D'Addato, A.V. 2006". "Progression to third birth in Morocco in the context of fertility transition". Demographic Research, 15: 517-536 (http://www.demographic-research.org/volumes/vol15/19/15-19.pdf).

D'Addato, A.V. 2006 . "Los determinantes de la fecundidad de las mujeres marroquíes en Italia y en el país natal: algunos modelos interpretativos", Migraciones, 20: 107-141, Universidad Pontificia Comillas, Madrid.

Deane Abernethy, V. 2002. Fertility decline; no mystery, Ethics in Science and Environmental Politics: 1-11. 
(http://www.int-res.com/articles/ esep/2002/article1.pdf)

Di Comite, L. and Moretti E. 1999. Geopolitica del Mediterraneo, Carocci, Roma.

Duben, A. and Behar, C. 1991. İstanbul Households Marriage, Family and Fertility 1880-1940. Cambridge University Press.

Easterlin, R.A. 1975. "An economic framework for fertility analysis". Studies in Family Planning, 6(3): 54-63.

Easterlin, R.A and Crimmins, E.E. 1987. The Fertility Revolution A Supply-Demand

Analysis. The University of Chicago Press, Chicago and London.

Eltigani, E.E. 2000. "Changes in family-building patterns in Egypt and Morocco: a comparative analysis". International Family Planning Perspectives, 26(2): 73-78.

Eltigani, E.E. 2001. "Childbearing in five Arab countries". Studies in Family Planning, 32(1): 17-24.

Eltigani, EE. 2003. "Stalled Fertility Decline in Egypt, Why?". Population and Environment, 25(1): 41-59.

El-Zanaty, F. and Way, A. 2001. Egypt Demographic and Health Survey 2000, Ministry of Health and Population (Egypt), National Population Council and ORC Macro, Calverton, Maryland.

Engelhardt, H. 2004. Egypt's Stalled Fertility Decline and Possible Role of Tempo Distortions. In Lutz W. (ed.). Population Network Newsletter, n. 36.

Fargues, Ph. 1988. "Baisse de la fécondité arabe". Population, 43(6): 975-1004.

Fargues, Ph. 2003. "Women in Arab countries: challenging the patriarchal system". Population et Sociétés, 387.

Giusti, C. and Vignoli, D. 2006. "Determinants of contraceptive use in Egypt: a multilevel approach". Statistical Methods \& Applications, 15(1): 89-106.

Hacettepe University. 2004. Turkey Demographic and Health Survey 2003. Hacettepe University Institute of Population Studies, Ministry of Health General Directorate of Mother and Child Health and Family Planning, State Planning Organization and European Union. Ankara.

Hancioğlu, A, Ergöçmen B., Ünalan T. 2004. The Population of Turkey at the Turn of 21st Century Past Trends Current Situation and Future Prospects. Population Challenges, International Migration and Reproductive Health in Turkey and the European Union Issues and Policy Implications. Turkish Family Health and Planning Foundation, İstanbul.

Hoem, J.M., Kreyenfeld M. 2006a. "Anticipatory analysis and its alternatives in lifecourse research

Part 1: Education and first childbearing”. Demographic Research, 15: 461 - 484.

(http://www.demographic-research.org/Volumes/Vol15/16/15-16.pdf).

Hoem, J.M., Kreyenfeld M. 2006b. "Anticipatory analysis and its alternatives in lifecourse research

Part 2: Marriage and first birth". Demographic Research, 15: 485-498.

(http://www.demographic-research.org/Volumes/Vol15/17/15-17.pdf).

Jejeebhoy, S.J. 1998. Women's Education, Autonomy, And Reproductive Behavior. Clarendon Paperbacks, Oxford University Press, New York.

Kertzer, D.I. 1997. The proper role of culture in demographic explanation. In Jones G.W., Douglas R.M., Caldwell J.C. and D'Souza R.M, The continuing demographic transition, Oxford, Clarendon Press.

Kleinbaum, D.G. 1996. Survival Analysis: A Self Learning Text. Springer-Verlag, New York.

Knodel, J. and van de Walle E. 1979. "Lessons from the past: Policy implications of historical fertility studies". Population and Development Review, 5(2): 217-245. 
Lesthaeghe, R. and Surkyn, J. 1988. "Cultural dynamics and economic theories of fertility change". Population and Development Review, 14(1): 1-45.

Mason, K.O. 1997. "Explaining fertility transitions". Demography, 34(4): 443-454.

McNicoll, G. 1994. Institutional analysis of fertility. WP n. 62, The Population Council, New York.

Mencarini, L. and Salvini, S. 2003. Mediterranean fertility: toward a South-North convergence?, Popolazione e Storia 2, Udine.

Montgomery, M.R. and Casterline J.B. 1996. Social learning, social influence, and new models of fertility. In Casterline J.B., Lee R.D., Foote K.A. (eds.), Fertility in the United States: New Patterns, New Theories. Population and Development Review, supplement to volume 22. Population Council, New York.

Notestein, F.W. 1953. Economic problems of population change. I In Eight International Conference of Agricultural Economists, Oxford University Press, London.

Paterno, A., Gabrielli G., D'Addato A.V. 2006. Travail des femmes, caractéristiques familiales et sociales: le cas du Maroc, WP 2006-052, Max Planck Institute for Demographic Research, Rostock.

Rodriguez, G. and Cleland J. 1981. "The effects of socioeconomic characteristics on fertility in 20 countries". International Family Planning Perspectives, 7(3): 93101.

Scrimshaw S. 1978. Infant Mortality and Behavior in the Regulation of Family Size, Population and Development Review, 4(5), 383-403.

State Institute Statistics (SIS). 1996. The Population of Turkey: 1923-1994, Demographic Structure Development. State Institute of Statistics, Ankara, Turkey

UNDP. 2006. Human Development Index Trends. Date of access 26.10.2006 (http://hdr.undp.org/statistics/data/pdf/hdr05_table_2.pdf).

United Nations. 2005. PRED Bank 4.0: Population, Resources, Environment and Development Bank. Population Division of the Department of Economic and Social Affairs, United Nations, New York.

United Nations. 2006. World Population Prospects: The 2004 Revision and World Urbanization Prospects: The 2003 Revision, Population Division of the Department of Economic and Social Affairs, United Nations, New York.

U.S. Census Bureau. 2006. http://www.census.gov/ipc/www/idbprint.html.

Vignoli, D. 2006. "Fertility change in Egypt: from second to third birth". Demographic Research, 15: 499-516 (http://www.demographic-research.org/volumes/vol15/18/15-18.pdf).

Watkins, S.C. 1986. Conclusions. In Coale A.J. and Watkins S.C. (eds.). The Decline of Fertility in Europe, Princeton University Press, Princeton.

Watkins, S.C. 1987. "The fertility transition: Europe and the Third World compared". Sociological Forum, 2(4): 645-673.

Yavuz, S. 2006. "Completing the fertility transition: Third birth developments by language groups in Turkey". Demographic Research, 15: 435-460

(http://www.demographic-research.org/volumes/vol15/15/15-15.pdf). 